Published by the University of Minnesota, College of Agriculture, Extension Division, A. D. Wilson, Director, and distributed in furtherance of the purposes of the cooperative agricultural extension work provided for in the Act of Congress of May 8, 1914.

\title{
CONTAGIOUS ABORTION OF CATTLE
}

By C. P. Fitch and W. L. Boyd, Division of Veterinary Medicine

The disease known as contagious abortion, infectious abortion, slinking, and dropping of calves is considered to be infectious in character. It should be kept clearly in mind that the term abortion means the birth of an immature fetus and that this is only one of the symptoms of this very complex disease. Contagious abortion is now generally considered to be closely related to sterility (failure to breed), due usually to inflammation of the uterus, diseases of the ovaries (especially cysts), inflammation of the Fallopian tubes (salpingitis), and other conditions. Contagious abortion is likewise the principal cause of retained placenta (afterbirth) and of the premature expulsion of a living fetus (premature birth) which often dies. This disease is often found closely associated with white scours of calves and calf pneumonia. To sum up, then, contagious abortion is probably the cause of a great deal of the trouble in the breeding of cattle and the failure to obtain healthy calves.

\section{HISTORY}

Abortion in epizoötic form (attacking many animals at the same time) has been known from very early times. For many years it was not recognized as infectious. In Denmark, where the ravages of the disease were especially marked, Dr. Bernard Bang, with his assistant Dr. Stribolt, in 1897 , found the cause, a small germ called Bact. abortus (see Plate I, Figure I). In England, a committee of the department of agriculture headed by Sir John M'Fadyean made a very complete report on this disease in Igog. Contagious abortion has spread rapidly in this country during the last ten years and is now known to be widespread and practically universal in its economic importance.

\section{Significance and Distribution}

Several years ago contagious abortion was estimated to cause an annual loss of $\$ 20,000,000$, but since that time it has rapidly increased. It is exceedingly difficult to make anything like an accurate estimate 
of the loss resulting from this disease, but an annual loss of more than $\$ 50,000,000$ can probably be directly traced to its ravages. At first it was confined to dairy cattle, but it has now spread to the beef breeds and to range cattle. The losses among this last class of animals are especially severe. Tuberculosis is still of great economic importance to cattle breeders, but contagious abortion is of equal significance and in fact may cause as much or even greater loss to the breeder. Its seriousness should be fully understood, since it strikes at the source of the breeding inclustry, the calf.

\section{CAUSE}

The cause of abortion is a short oval-shaped germ (Bact. abortus) about I.5 microns in length. (A micron is one twenty-five thousandth of an inch.) Artificially it is rather difficult to cultivate at first, but after one or two generations of transfers it grows quite readily. In the diseased cow the organism lives in the mucous membrane lining the genital organs, especially the uterus. It has also been found in the milk and ulders of animals which have aborted, and in certain instances in the milk of those which have not been observed to abort. Abortion bacteria also inhabit the intestinal canal of the infected fetus and may be isolated in pure culture from this source. Outside the animal body, little is definitely known concerning its distribution. Observations and experience seem to indicate that this germ is able to live for some time on litter which has been soiled by the discharge from aborting cows. It has not been isolated, however, from any source where its presence could not have been accounted for as coming from an infected animal. The germ is easily clestroyed by disinfectants and heat. A $2 \frac{\mathrm{T} / 2}{2}$ per cent solution of cresol clestroyed the organism in fifteen minutes. A temperature of from 55 to 60 degrees, C. (I 3 I to I40 degrees, F.) kills the organism in ten minutes.

\section{PATHOGENESIS (METHOD OF DEVELOPMENT)}

The inoculation of pregnant cattle either by feeding or by the in-. jection of the germ intravenously (into a vein) produces abortion after a variable length of time. Sometimes such animals go to full term and give birth to a fully developed calf. Such an inoculated animal may abort during a future pregnancy. Bact. abortus produces a disease in guinea pigs which in appearance resembles tuberculosis. It also causes pregnant guinea pigs to abort. The germ has been found in calves affected with white scours, and it is quite probable that it has some etiological, or causal, relationship to this disease. According to Williams, retained placentas are due primarily to the abortion infection. ${ }^{1}$

1 Williams, W. L. Retained placenta. Cornell Veterinarian, Vol, VIII (1918), p. 63. 


\section{Channels of Infection}

The natural channels of infection seem to be (I) the digestive tract and (2) the genital tract. Experimentally, abortion can be produced by the germ introduced into either place.

Some investigators hold that the cervical canal (see Plate I, Figures 2 and 3 ), open at the heat period, is the chief aventue of infection, the germs being introduced into the neck of the uterus and the uterus proper at the time of coptlation (breeding). No doubt the bull is responsible for the transmission of the clisease in a great many cases, especially in herds where only one sire is used to serve both diseased and healthy cows. In albortion occurring among range cattle, the bull is probably responsible for carrying the infection from one cow to another, principally at the time of breeding. The digestive tube undoubtedly is also one of the chief channels of entrance, the infection being obtained from contaminated foodstuffs, including pastures where diseased animals are allowed to graze. Heifer calves allowed to nurse aborting cows, or fed on milk which contains the germs of abortion, probably become infected early in life. The disease has been produced artificially by feeding infected material, and by injecting active abortion germs into the veins and under the skin; also by inserting pieces of the afterbirth from an aborting animal into the vagina of a pregnant cow.

\section{SUSCEPTIBILITY TO ABORTION}

Contagious abortion is chiefly a disease of heifers, but adult cows may and often do abort. Many heifers will abort once and then carry their second calf for the full period of pregnancy. A less number will abort the second calf and occasionally a cow aborts the third time. Cows and heifers reared in non-infected herds frequently abort after being put on infected premises. Infectious abortion is not confined to any breed or type of cattle.

\section{SYMPTOMS}

The period of incubation, or the time elapsing between the exposure of an animal to infection and the development of the signs of the disease, varies. According to Bang it is about ten weeks." In producing the disease experimentally, certain workers have determined the period of incubation to be approximately one hundred and thirty days. The symptoms or signs preceding the expulsion of the fetus, when noticed, are a doughy-like swelling of the uclder ("making bag") together with swelling of the vulva, followed by a mucous-like odorless discharge from the vagina. Restlessness and stamping of the hind feet may also

2 Bang, B. Infectious abortion in cattle. Jour. of Comp. Path. and Therap., Vol. XIX (1906), D. I9I. 
be noticed. These symptoms usually appear two or three days before the fetus is expelled. Occasionally heifers have been observed to make bag and even lactate at the sixth month of gestation, the abortion not taking place until alout the seventh month. Swelling of the udder in advanced pregnancy does not always indicate infectious abortion, since heifers usually make bag a few months before parturition (giving birth).

Cows will sometimes abort without manifesting any symptoms beforehand. When heifers or cows abort in the early stages of pregnancy, the fetus will be expelled enclosed in its membranes, but when the abortion occurs after the fifth or sixth month of gestation, the membranes (afterbirth) are frequently retained. The largest percentage of observed abortions takes place between the fifth and seventh months of pregnancy, altho abortion may occur at any time during the period of gestation. It is important to take into consideration the fact that an animal may abort cluring the first or second month of pregnancy and the act pass unnoticed. Following abortion, some ex. citement may be noticed in cows and at times they will show signs of being in heat. The discharges following an abortion continue for two weeks, or longer if the lining of the uterus is severly inflamed. 'The discharge is clirty yellowish-gray in color, sticky in character, and accumulates on the tail and other parts with which it comes into contact. The appetite is impaired, the back is arched, and there is more or less straining, due to the irritation of the uterus. The milk flow is slight at first and one or more quarters of the udder may remain swollen for several clays. The calf is born clead, as a rule. If alive, it dies shortly after birth.

The ealf born alive is usually weak and undersized and often dies from diarrhoea or remains in a stunted condition. In rare cases the fetus becomes mummified (dried up). In every herd where abortion occurs or gains a foothold, a certain percentage of the animals that have aborted and apparently recovered from the effects of the disease will fail to conceive (breed), though served by the bull numerous times. Such animals are known as non-breeders.

Failure to breed is, in most cases, probably due to inflammation of the lining of the uterus, or to pus in the uterus (see.Plate III), often the result of retained afterbirth. Cystic degeneration of the ovaries (see Plate IV) is not uncommon in aborting cows and is undot1btedly responsible, in certain cases, for temporary or permanent failure to breed. Cows in which the ovaries are extensively degenerated (see Plate V), have irregular and frequent heat periods, and tho they be bred numerous times, fail to conceive.

To sum up, then, the observed act of abortion is only one of the symptoms of this disease. The animal may abort during the early 
stages of pregnancy and the fact pass unnoticed, the owner simply thinking that she dicl not conceive at the previous service. Discharges from the vagina, especially of a brownish or yellowish color, abundant, and at first odorless, are indicative of the infection. Failure to breed is usually the result of infection by Bact. abortus. Siclily or unthrifty calves or calves suffering with scours are also closely associated with the abortion infection.

\section{HOW ABORTION IS SPREAD}

The mucous lining of the uterus of infected heifers and cows harbors the Bacl. aborlus. The contents of the uterus, such as the fetus, fetal membranes, and fluids, contain myriads of the organisms and when expelled become vehicles by which the disease spreads. The discharge from the vagina and uterus, following abortion, contains numerous germs which may be carried to various parts of the stable by surface drainage. Attendants may carry the infection on their clothing or on the milking utensils. The bull may be a frequent carrier of the infection, especially if several breeders use the same animal. lnfected, pregnant heifers or cows introduced into healthy herds of ten establish new centers of the clisease when they abort. This is probably one of the chief ways in which the clisease spreads, since it is impossible to determine by a physical examination whether a cow is infected. The discovery of abortion bacteria in the milk of aborting cows may prove an important factor in the control of the clisease.

Abortion is often conveyed from herd to herd by the introduction of a diseased cow. This animal infects the herd bull and he in turn transmits the clisease to the other members of the herd. Or, as sometimes happens, a bull is bought from an infected herd and brought to a clean herd or to one in which the disease exists in a nild form, and by serving the cattle sets up or intensifies the infection:

Taking into consideration the foregoing facts, the breeder will readily appreciate the need of good stable sanitation, the proper disposal of infective material, and the danger of introducing new animals into the herd.

\section{DIAGNOSIS}

If several abortions have occurred in a herd, and especially if the aborting animals are heifers, there is little doubt that the animals are infected with contagious abortion. It may affect several of the older cows before appearing in the younger animals. The history of the herd, such as the purchase of new heifers or cows which may be infected and abort shortly after being introduced into the herd, or the use of a sire that has become infected by serving cliseased cows, should be carefully noted, for these facts are often valuable in making a cor- 
rect diagnosis. When infectious abortion cannot be diagnosed in this way, the following methods may be used:

( I) Bacteriological, or a study of the invading bacteria; (2) Serological, or examination of samples of blood from infected cows.

\section{Bacteriological}

Bacteriological diagnosis may consist of a microscopical examination of smears, prepared from the stomach and intestinal contents of the calf, soon after it is dropped. Smears made from the vaginal discharge and the afterbirth may also be employed. If small, short rodshaped germs are found in large numbers, they are suggestive of the presence of contagious abortion.

It is necessary, however, before they can be positively identified to obtain them in pure culture on artificial media (material such as beef broth in test tubes in which bacteria can grow) and study their cultural characteristics. It is often very difficult and sometimes impossible to obtain Bact. aborhus in pure culture when it is present in discharges in connection with other bacteria. The other germs multiply more rapidly than the abortion organism and hide it.

\section{Serological}

The serological method of diagnosis, which is widely used in the recognition of other diseases, such as typhoid of man, and glanders and clourine of horses, has also been used with more or less success in the diagnosis of contagious abortion. With the exception of the collection of blood samples from suspected animals, this method is purely a laboratory procedure. From i 5 to 30 mils (one half ounce to an ounce) of blood are drawn from the jugular vein of the animal by means of a hypoclermic needle and examined for the presence of certain substances called "antibodies." This examination requires consiclerable time and much technical skill.

The practical value of this method of cliagnosis is questionable. Experiments are being conducted at the Minnesota Experinent Station to determine if possible just what dependence should be placed on the results of these tests. A positive reaction to these tests does not mean that the animal from which the blood was drawn has aborted or will aborl. In our experience negative reactions do not assure one that animals will not abort during the present or future pregnancies. Probably all these reactions show is whether an animal ever has been or is infected with Bacl. aborlus. We doubt the practical value of these tests in the control of contagions abortion.

\section{PREVENTION AND TREATMENT}

The most successful method of treating contagious abortion is to prevent its spread. Various drugs have been used for its prevention 
and treatment, and while the results obtained vary considerably, none have proved to be of great value. There is yet no reliable cure for contagious abortion. The eradication of this disease demands extreme cleanliness and careful disinfection, not only for the animals, but also for their surroundings. In launching a campaign against infectious abortion, a large amount of extra work for an indefinite period must be done. In herds where abortion has recently appeared, it is advisable to separate the aborting cows, not allowing them to come into contact with healthy cattle until all signs of the disease have clisappeared. In herds where the disease is widespreacl this is not necessary.

If a separate stable is not available, the cliseased cows should be kept in one end of the building. Inmediately following an abortion, the fetus and afterbirth should be taken from the stable and destroyed either by burning or by burying, for the abortion germs are extremely numerous and active from these parts. The discharges from the womb and vagina should be treated with disinfectants, since the organisms are also numerous in this material.

These precautions do not eliminate all the sources of infection, for sometimes an animal which has never been known to abort is nevertheless scattering the germs. But they do look toward the proper clisposal of certain of the most active sources of infection; and go to make up good stable sanitation which should be practiced by every breeder whether his herd is affected with contagious abortion or not.

\section{Care of Animal During Pregnacy and Parturition, and Care of New-Born Calf}

The proper handling of cows during advanced pregnancy is a very important part in the general canpaign against this disease. When the cow has reached her $270 t h$ day of pregnancy, or even earlier if it seems probable that she is going to calve sooner, remove her from the herd and give her a bath with soap and warm water. Do this thoroly. After this is clone, rinse the animal with clean water and apply a mild disinfectant such as a 2 per cent solution cresol compound, creolin, or bacterol. Place the animal in a clean, clisinfected box-stall. It should be kept clearly in mind that thoro cleansing is worth as much as disinfection, if not more. It is exceedingly difficult, if not impossible, thoroly to disinfect a dirty stall. After the washing, bathe the tail, udder, vulva, and thighs daily with a warm solution of the disinfectant. It is sometimes advisable to clouche the vagina daily with a saline or Lugol's solution (see Treatment).

When the calf is born, rub dry with a clean cloth. Disinfect the stump of the navel cord with a I-IOOO corrosive sulblimate solution (tablets of this material may be purchased at any drug store) by placing the solution in a tumbler. Stand the calf on its feet and im- 
merse the stump in the tumbler of clisinfectant. Keep it submerged for ten or fifteen minutes. The navel stump may now be dusted with a styptic powder composed of equal parts of boric acid and powdered alum. Put the new-born calf in a clean stall and if possible keep the calf by ilself for the first two to three months.

Owing to the fact that the abortion organisms are given off in the milk of some infected cows, while others suffering with retained afterbirth or inflammation of the uterus discharge fluids which stain the inside of the legs and udder, the nursing calf or the calf fed on mixed raw milk from a pail undoubtedly may become infected early in life. We are of the opinion that, in herds where abortion exists, the calf should be separated from the cow within eight or ten days after birth and fed on pasteurized or boiled milk. Calves fed in this way are less likely to become infected with the abortion germ and also with the Colon group of organisms which frequently cause scours and pnenmonia of young calves.

Very recent research work at the Michigan Agricultural college tends to show that new-born calves do not always become infected with Bact. abortus from milk," To pastenrize or boil the milk fed to newborn calves, however, is excellent prophylaxis (prevention), not only for abortion, but also for infection with white scours, tuberculosis, and other diseases. If the calf is a strong, lusty animal, it may be well to separate it from the cow immediately after birth and not allow it to nurse its mother at all.

\section{Treatment of Animals Affected With Abortion}

The genital passage (vagina) should be irrigated with a mild antiseptic or saline solution. More and more we are becoming convinced that coal tar disinfectants should not be employed as clouches for the genital tract. We agree with the noted Danish veterinarian, Doctor Albrechtsen who says, "I have used many disinfectant solutions or astringents, some stronger, some more dilute, but experience has shown me that mechanical cleansing is of chief importance while disinfection of the mucosa seems to be of less value."

If an antiseptic is used, Lugol's solution of iodine is recommended. This should be used in one-half of I per cent solution, which is approximately one tablespoonful of the iodine solution to a gallon of lukewarm water. If the saline solution is used, add two small tablespoonfuls of common salt to a gallon of warm water. We recommend the saline solution unless considerable sepsis (decomposition) and foul odor are present. One gallon of the solution should be used at each washing. A soft rubber tube one inch in cliameter may be used, one

\footnotetext{
3 Huddleson, I. F. The transnission of Bacterium abortus (Bang) to new born calves through the ingestion of milk. Mich. Agr. Exp. Sta. Tech. Bull. 32. 1916,
} 
end of which is introduced into the vagina, the other end being furnished with a funnel into which the solution is poured and which is elevated so that the fluid will gravitate toward the uterus. Where a large number of cows are being treated, a bucket may be fitted with a faucet at the bottom to which the rubber tubing may be attached. The pail can easily be suspended on a wire stretched from one end of the barn to the other. The irrigation should be repeated claily for at least ten clays, and then twice a week until the discharge has ceased. The external genital organs, the tail, and the inside of the legs should be sponged with a warm antiseptic solution twice the strength of the solution used in irrigating the internal organs. This treatment should be applied claily to every cow in the stable. If the afterlirth is retained, it should as a rule be removed within forty-eight hours following the abortion. In case the afterbirth cloes not come away readily, the uterus should be flushed once or twice daily with the warm saline solution, until the membranes cone away. Successful removal of the afterbirth is important, and if possible, a skilled veterinarian should be employed.

\section{Breeding of Cows That Have Aborted}

An animal which has aborted should not be re-bred until her genital organs are healthy. A healthy condition of the organs usually can be restored with proper care, altho some animals will remain diseased even after the best treatment yet known has been applied. It is folly to breed a cow which has a discharge from the uterus. She will not only be tunlikely to conceive but she will also expose the bull to a virulent infection, thereby tencling toward the spread of the disease in the herd. And further, in case the cow does conceive, the fetus will very frequently be expelled while quite small and in a short time the "heat" period will recur. As stated, many abortions of this type are not noticed.

It is impossible to say how long a time is necessary for the genital organs to become healthy. In some animals, with the proper treatment applied, it may not be more than from thirty to sixty days. In other animals it occasionally takes months of careful treatment to bring albout a normal condition. The advice and services of a conpetent veterinarian are a necessity in cases which stubbornly refuse to respond to treatment.

\section{Treatment of the Sire}

The bull may be prevented from carrying the infection by disinfecting and mechanically cleansing the penis and sheath before and after each service. The same kind of an apparatus can be employed as is used for douching the cows, except that the rubber tube will be too large to enter the sheath of the bull freely. For this purpose onc 
should employ a pure-gum horse catheter. Lugol's solution in one-half of I per cent dilution should be employed. (One teaspoonftal to a quart of warm water.) The sheath should be held by the hand so that it will be distended and the fluid will not immediately escape. The long hair around the opening of the sheath should be clipped and the surrounding parts bathed in the antiseptic solution.

\section{Treatment of Sterile Cows}

Sterility, temporary or permanent, is a frequent sequel to abortion, and is often the result of retention of the afterbirth. In cows that fail to clean, certain pus-forming organisms gain entrance to the genital passages where they ause temporary or permanent changes (see Plate II, III, and IV). In herds where sterility exists, there is a decrease in milk production, as well as a failure to produce calves for the renewal of the herd. In a great many instances farmers and breeders breed sterile cows every time they appear in heat. Frequent service of the nonbreeding cow not only aggravates the condition of the cow but endangers the health of the sire as well. The treatment of sterility requires surgical skill and lknowledge and should be attempted only by expert veterinarians. All cows that fail to breed should be examined, the incurable ones sent to slanghter, the others treated and put into service again as soon as possible. It is false economy to sell an animal just because she has aborted. Keep her and treat her until she is known to be sterile.

\section{Immunity}

Whether there is any lasting immunity to contagious abortion is still a clisputed question. It is often observed, however, that aninals rarely abort more than two or three times. That oller cows suffer less than young ones from abortion is a fact which Willians (Abortion and sterility of cattle. Report New York State Veterinary College, I9I I-J 2, p. 79) attributes to a natural age immunity. This tendency toward an immtnity has acted as a stimulus to investigators in the attempt to produce an artificial immunity. The hope of controlling the infection by vaccination has not yet been fully realized. Investigations conducted by certain workers in which living and clead cultures of the abortion germ were used indicate that there may be a possiljility of producing artificial immunity.

\section{Treatment of White Scours and Pneumonia in Calves}

White scours and calf pneumonia frequently accompany abortion and are responsible for heavy losses of life. The treatment, as in abortion, is mainly preventive, and includes clisinfection of the navel cord with corrosive sublimate in a $\mathrm{I}$ to $\mathrm{I}, 000$ dilution or with tincture 
of iodine or some other equally good antiseptic, together with cleanliness of calf pens, pails, and all utensils. Injecting the new-born calf with calf scours serum is now practiced as a preventive measure. When the infection is present in a herd, the healthy calves should be separated from the diseased ones, and fed pasteurized or boiled milk. The stable should be thoroly cleaned and clisinfected. Calf scours serum should be given to all calves not in the arlvanced stages of the disease. Incurable cases and calves not worth treatment should be destroyed and the carcasses disposed of by burning or burying.

\section{Stable Sanitation}

As a precautionary measure in the establishment of herd hygicne, it is advisable to practice stable disinfection. Stables, whether infectecl or not infected, should be liept clean and free fron the accumulation of manure and dirt. Frequent spraying of the floors, gutters, mangers, and walls with Kreso dip or some other equally good disinfectant will be found beneficial. Keeping unslaled lime in the gutters is thought to be helyful altho the disinfecting properties of this material are probably very slight. Stables known to be infected should be thoroly cleaned and disinfected. Remove all animals from the barn for five or six days. The interior of the stable, including the floors. gutters, mangers, walls, and ceiling, should be freed of all dirt ancl dust. This should be clone by the liberal use of soap and hot water. When the barn is clean, a strong disinfectant such as a 3 or 4 per cent solution of creolin should be applied to the stalls, gutters, and walls. This may be clone by the use of a spray pump. Whitewashing is advisable in many stables, as it not only acts as a disinfectant but makes the interior brighter and lighter. The linewash should be applied only after the barn has been made scrupulously clean. The addition of chloride of lime, eight ounces to each gallon of whitewash, will increase its disinfecting properties. Whitewash is best applied by the use of a spray pump such as is used in the spraying of orchards. The solution nay then be forced into all the cracks and crevices of the barn with little or no difficulty.

\section{SUMMARY}

I. Infectious abortion is widespread and from an econonnic standpoint is probably the most important disease affecting cattle.

2. The disease may exist in herds wherein apparently healthy calves are being dropped, yet retention of the afterbirth sometimes followed by sterility indicates the presence of the infection.

3. The act of abortion, or the premature expulsion of the fetus from the uterus is only one symptom of this chronic infectious disease of the genital organs. 
4. Owing to the prevalence of abortion and the extensive distribution of the germs, together with the rarity of abortion from other causes, one is ustally safe in deciding on the nature of the disease from the history and symptoms of the affected animals.

5. A laboratory examination of the blood of heifers or cows seems to be of little practical value in the control of this disease.

6. White scours and calf pneumonia are often found to co-exist in herds affected with abortion and are thought to be closely related.

7. No drugs have yet been found that will cure or prevent this insidious disease, altho much can be accomplished in the way of control and eradication by the proper treatment and by practicing rigid sanitary measures.

8. As the treatment of aljortion is mainly through prevention, strict hygienic measures such as irrigating the vagina of the heifer or cow before breeding, and irrigating the sheath of the bull both before and after service should be practiced in all herds.

9. The use of vaccines in the control of this disease is still in its experimental stage.

Io. The treatment of sterile or non-breeding cows requires surgical knowledge and should be attempted only by competent and skilled veterinarians. 


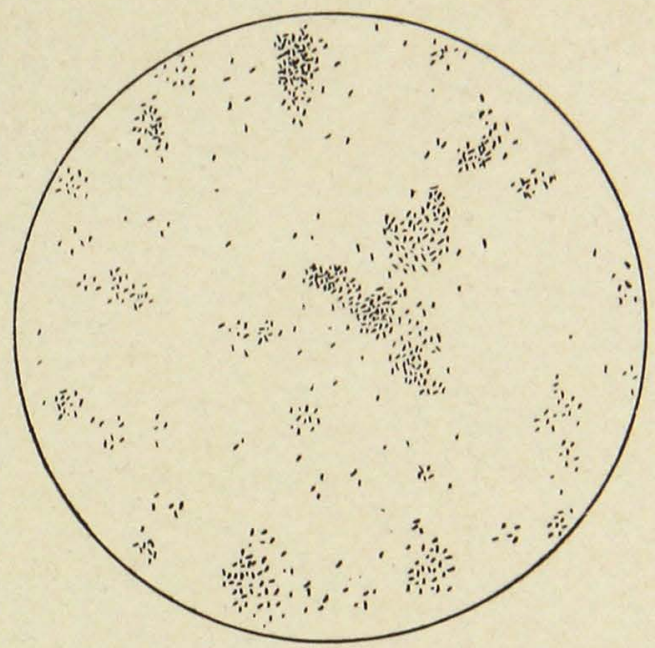

Fig. I. Bact. abortus, the Germ Causing Contagious Abortion. Magnified 700 Times
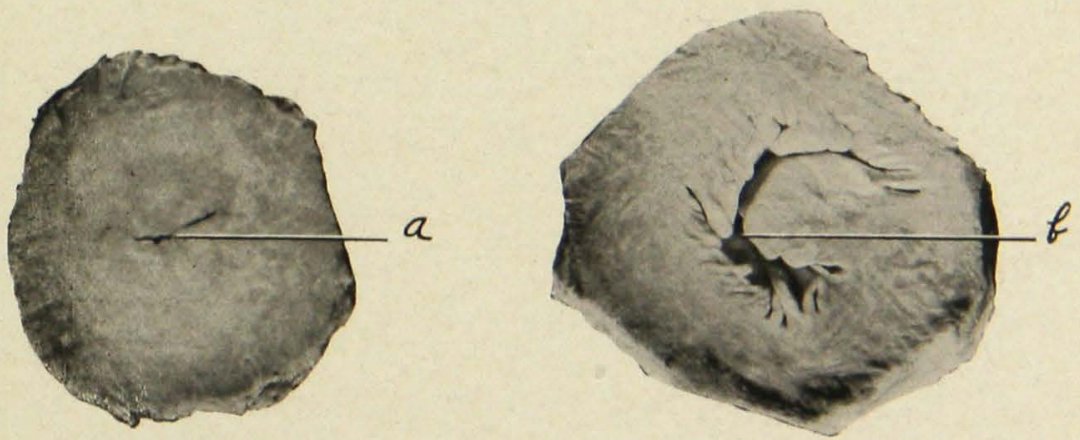

Fig. II. a. Cross-Section of Cervix or Neck of Womb Showing Normal Small Passage From Vagina to Womb

b. Same Passage Nearer the Vagina

This opening is completely closed only when the animal is pregnant, and contrary to popular opinion seldom requires "opening" in order for the animal to breed. 
Plate II

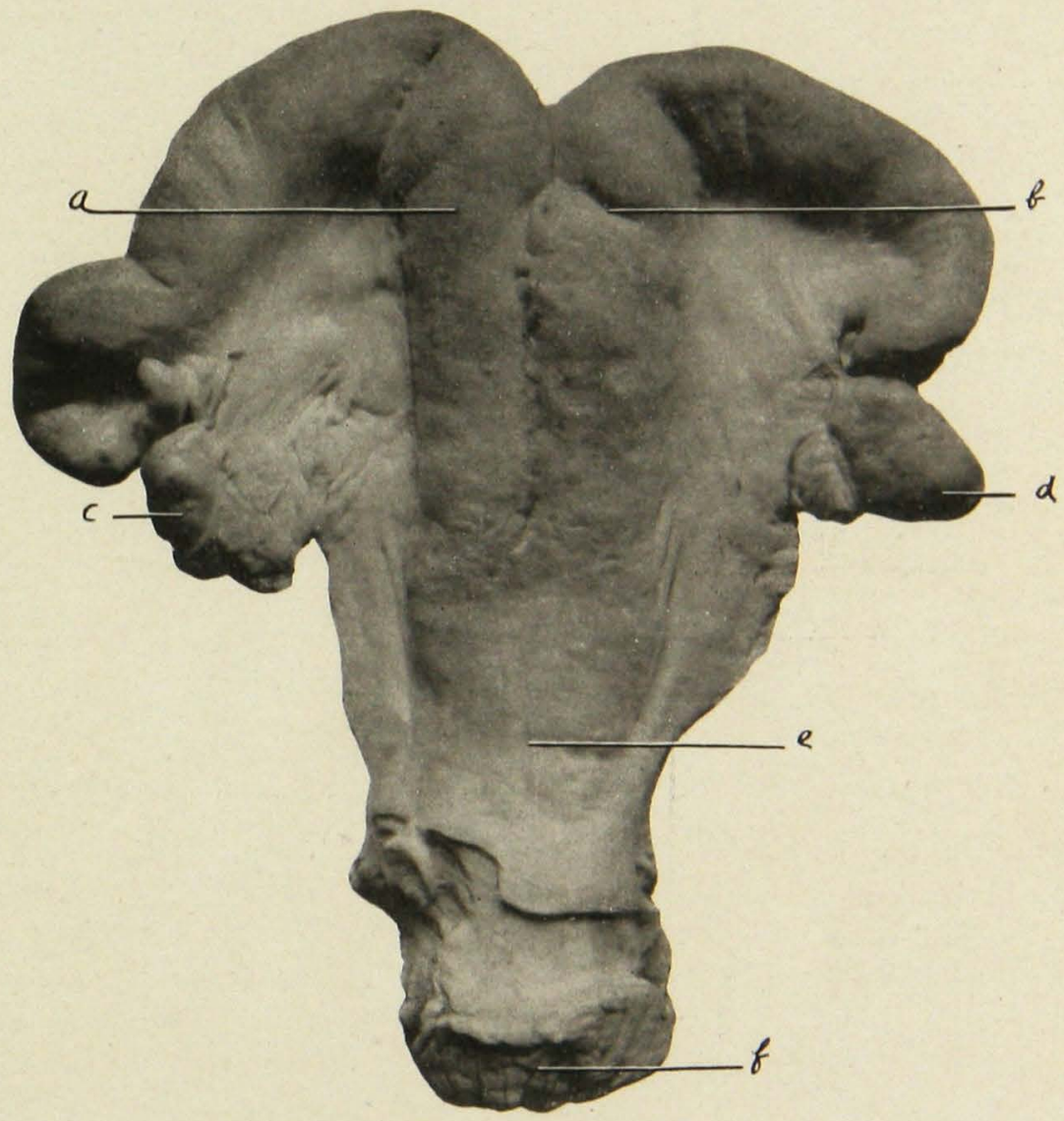

Normal or Healthy Uterus of the Cow
a. Left horn of uterus
d. Right ovary
b. Right horn of uterus
e. Body of uterus
c. Left ovary
$f$. Cervix of uterus 
Plate III

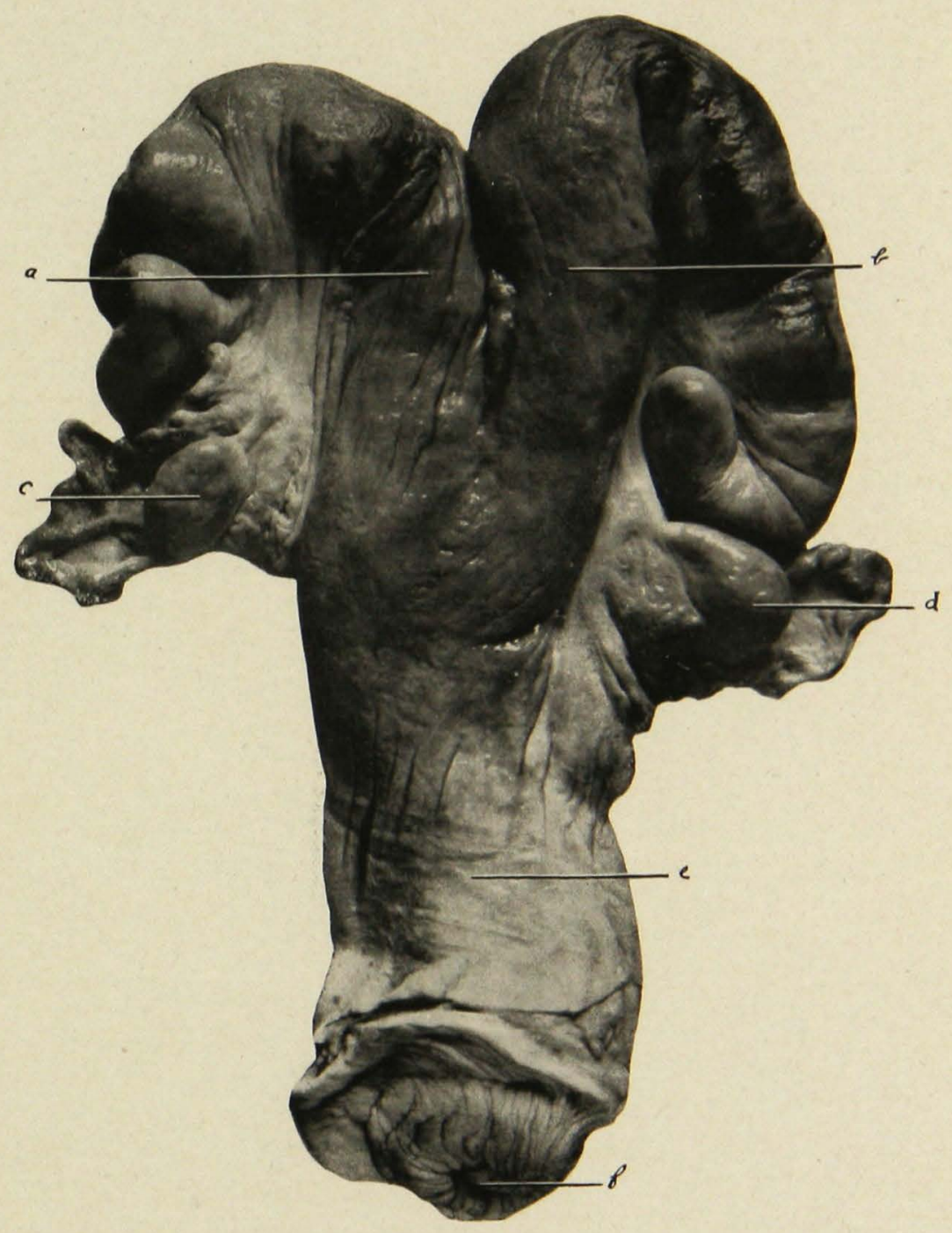

Diseased Uterus of Non-Breeding Cow (Notice increase in size.)
a. Left horn of uterus
d. Right ovary
b. Right horn of uterus
e. Body of uterus
c. Left ovary
f. Opening of cervical canal 


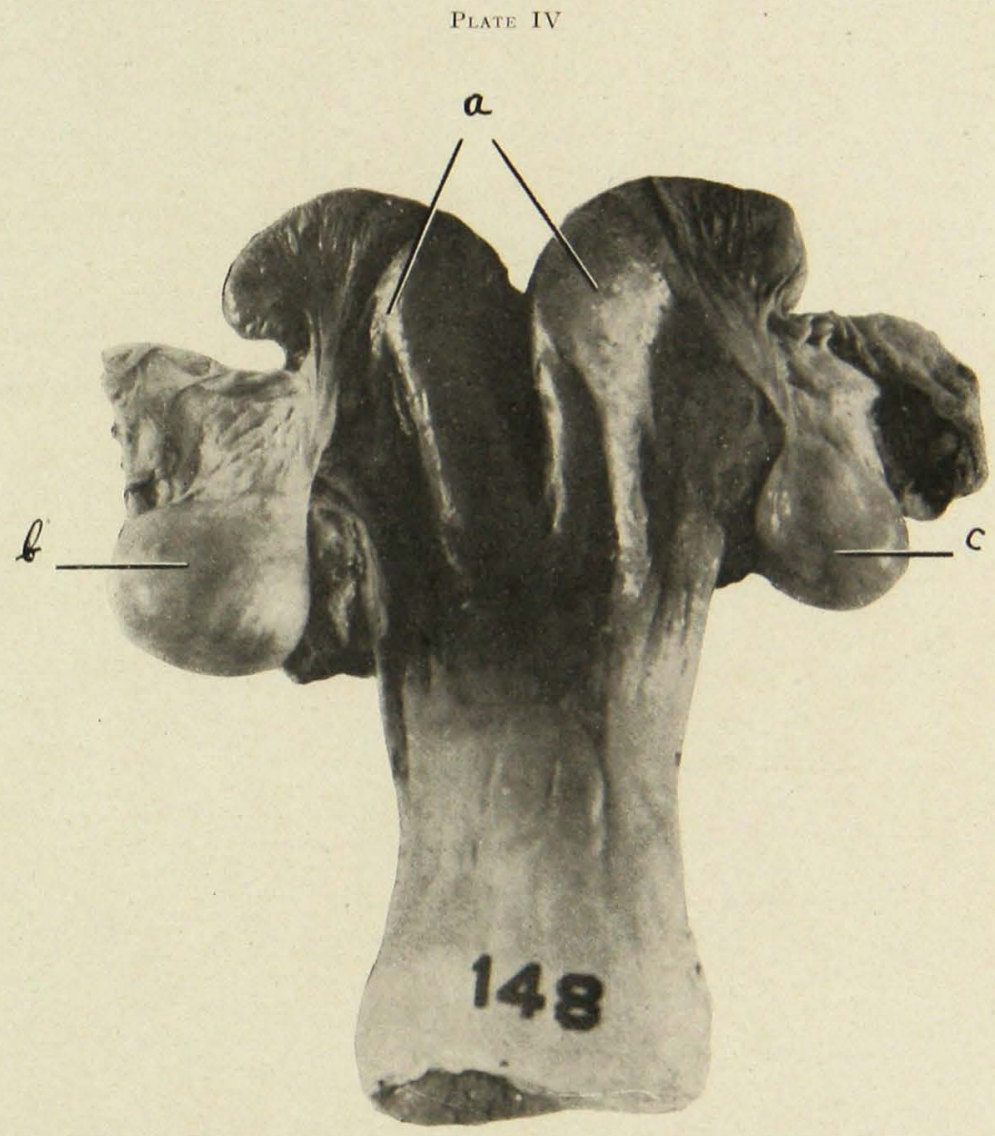

Uterus and Large Diseased Ovaries Which Are Cystic, From a Non-Breeding Cow a. Horns of uterus

b. Cystic ovary, left

c. Cystic ovary, right 
Plate V
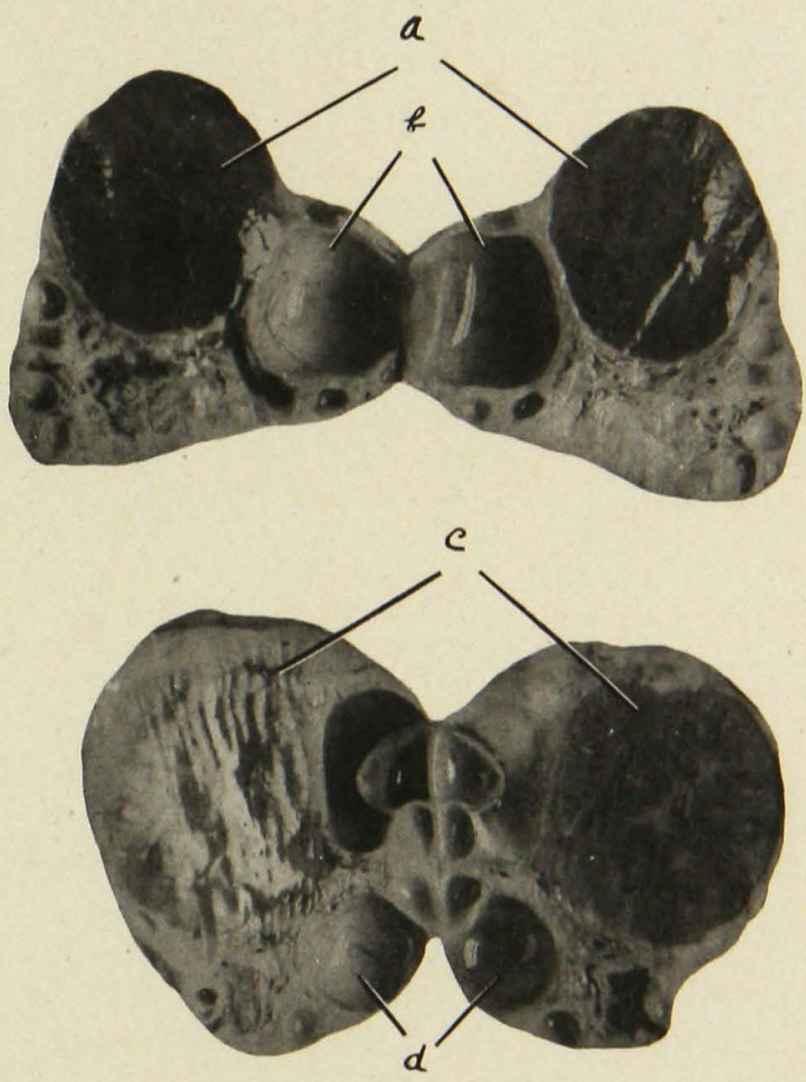

Cystic Ovaries Cut Open

a. and c. Corpora lutea or yellow bodies

b. and d. Cysts

This shows cavities and also yellow bodies, "Corpora lutea," which may persist in the ovary and prevent conception. 